\title{
ORGANIZACIÓN DEL ABASTECIMIENTO DE TRIGO Y PRODUCCIÓN DE PAN EN CÁdIZ DURANTE LOS AÑOS 40 (1).
}

\author{
JUAN IGNACIO VALLEJO SÁNCHEZ \\ Universidad de Cádiz
}

\section{PAUTAS GENERALES DE LA ORGANIZACIÓN DEL ABASTECIMIENTO Y EL CONSUMO DE PAN EN ESPAÑA.}

La existencia de una política económica dirigida por el estado encaminada al control y organización del abastecimiento de trigo, harinas y productos panificados resulta innegable en la Historia contemporánea de nuestro país. El abastecimiento de un producto tan imprescindible como el pan preocupó siempre, de un modo u otro, a las autoridades públicas, debido a la problemática que conlleva una población infralimentada. El Estado que sobrevino tras el final de la Contienda Civil española no menospreció esta circunstancia y, dentrode su filosofía política y económica, creó todo un aparato de control y gestión de esos bienes. Los mecanismos empleados por el Estado siguieron fundamentalmente dos direcciones, poco innovadoras en general (Barciela 1985: 295): el control de la producción de los cereales, de acuerdo a las preemisas económicas quea adjudicaban un papel subsidiario a la agricultura (Eiroa 1995: 103-108), y el control de la comercialización y el consumo a través de una política dirigida de precios, que ignoraba los comportamientos de éstos en una economía de corte capitalista (Barciela 1985: 285,301) (2) y por medio de un estricto sistema de regulación de consumo racionando las existencias.

Toda esta labor de control se concretó en una serie de organismos y fórmulas de los que el más importante es la Comisaría General de Abastecimientos y Transportes (3). Este organismo, creado en 1941, centraliza toda la labor de control de la economía de consumo, a través de una jerarquía piramidal de comisarías regionales, delegaciones provinciales y locales y un amplio aparato burocrático.

Con el objeto de facilitar el acceso de los productos a la población, los precios se establecían a la baja y por decreto, fijándose por medio de organismos específicos: las Juntas Harino-Panaderas (1937-1945) y las Juntas Provinciales de Precios (1945-1952) (4). La distribución a los consumidores finales de la producción cerealera -como del resto de los productos considerados de primera necesidad- se organizaba a través del sistema de racionamiento (5). Según éste, cada ciudadano tenía derecho a una determinada ración de cada producto, cuya cuantía podía variar en virtud del sexo, edad y ocupación.

La efectividad de todas estas políticas gubernamentales se vieron muy limitadas por su erróneo enfoque inicial y por dos taras que hipotecaron cualquier posibilidad de éxito. En primer lugar, nunca se contó con un adecuado cuerpo de estudios estadísticos sobre la producción de cereales y el consumo de 
los mismos (Barciela 1983: 666; Id. 1985: 285). Esta dificultad es constamente tratada por la documentación legal generada por los distintos organismos competentes. La consecuencia directa de esta carencia es el desconocimiento de la realidad sobre la producción de cereales y el abastecimiento de los mismos y de las manufacturas panificadas. En segundo lugar, tampoco se tuvieron en consideración los mecanismos económicos del mercado triguero, ni siquiera los más elementales, subyugándose éstos a la ignorancia de las clases gobernantes o a los intereses particulares de determinados sectores de la sociedad española (Id. 1985: 285, 301).

\section{LAS RESPUESTAS DE LA POBLACION: EL MERCADO NEGRO.}

La ineficacia del sistema de organización de abastecimientos para satisfacer las necesidades reales de la población española obligó a ésta a buscar vías alternativas para resolver la situación de escasez que le acuciaba. Surgió así un mercado paralelo al oficial que cubría la demanda real de esa población (Moreno 1995: 118; Barciela 1986a: 393; Id. 1985). El grave desequilibrio entre los precios oficiales de los productos y los precios naturales del mercado provoca una pérdida de rentabilidad en las producciones de los agricultores de cereal , lo que anima a éstos a la restricción de su cutivo en favor de otros de venta libre. Al caer los rendimientos, cae la producción (Barciela 1986a: 393) y en consecuencia una disminución de la oferta en una tendencia de alza de la demanda (Id. 1985: 286-287). Negada -o desconocida- esta situación por el mercado oficial, el mercado negro, al margen de la ley, se erige en el marco alternativo de obtención de productos básicos. Los precios de los productos de estraperlo estaban muy por encima del oficial (hasta el triple (Eiroa 1995: 143), variando su cuantía según el desequilibrio existente entre los precios oficiales y los naturales, los riesgos de sanción y la oferta y demanda existentes en esos momentos (6).

En el caso del pan, su consumo tenderá a aumentar a medida que disminuyese el nivel de renta, cuyo ritmo de crecimiento es muy inferior al de los precios (tanto oficiales como ilegales) (7), y a medida que se disparen los precios de otros productos. Estas circunstancias, unidas a la escasez de productos como la carne, la leche, los huevos, etc., desencadenaron en los años 40 un importante aumento de la demanda de pan. Consecuencia inmediata de esto es un aumento del precio (gráfico 1) y de la cantidad comercializada (8).

\subsection{El peso de los productos panificables en el mercado negro gaditano.}

A nivel peninsular, los mayores volúmenes de transacciones comerciales ilícitas tenían como principal protagonista al trigo, auténtico "producto rey del estraperlo" (Barciela 1986b). Las fuentes que nos sirven para estudiar el mercado negro de este cereal (y otros panificables) es la documentación emanada del S.N.T. y de la Delegación Provincial de la C.G.A.T. Para el caso de Cádiz, he encontrado serios obstáculos para indagar sobre este asunto debido a 
que la documentación de la Delegación Provincial del S.N.T., con sede en Jerez de la Frontera, no está a disposición del público. De la dispersa información que ofrecía la Delegación Provincial de la C.G.A.T., en el Gobierno Civil, he buceado en la documentación de la Inspección Provincial de Abastecimientos buscando infracciones referidas a mercadeo ilegal de cereales, harinas panificables, etc. Así mismo, he usado los expedientes del Tribunal de Contrabando de Cádiz con idéntica finalidad y los BOPCA buscando órdenes, circulares, etc. que me diesen alguna pista sobre la práctica del estraperlo de trigo y sus derivados en la ciudad de Cádiz. Los resultados no han sido muy alentadores; sin embargo, las posibilidades de investigación subsisten y sólo es necesario dirigir los pasos por nuevos caminos, de los que trataremos más adelante. Analicemos ahora el panorama del mercado negro de trigo en el ámbito nacional de la mano de Barciela (1983 y 1986).

El mercado negro de trigo tuvo una gran importancia cuantitativa que llegó a superar el volumen de las transacciones del mercado oficial (Barciela y García 1983: 198, gráfico 2) si bien el mayor control al que fue sometido el trigo por parte de las autoridades hizo que los porcentajes de ocultación fuesen menores que los de otros productos. El peso específico de esta actividad fraudulenta variaba según se tratara de zonas excedentarias de cereal o deficitarias, siendo mayor en éstas últimas, como pudo ser el caso de Cádiz (9). Los principales actores de este mercado solían ser los productores y comerciantes, con la complicidad a menudo del funcionariado público. El peso de la ley jamás caía sobre estos grandes estraperlistas y se cebaba principalmente en los contrabandistas más modestos que traficaban para ganarse el sustento (10).

A pesar de la evidente realidad del fenómeno del estraperlismo, las autoridades intentaron negarlo oficialmente no reconociéndole estadísticamente: Esto haría que las estadísticas generadas entre 1935 y 1953 careciesen de calidad y ofrezcan dificultades a los historiadores para estudiar los problemas de la agricultura española en ese tracto temporal.

¿En qué medida estas características generales con válidas para el ámbito de Cádiz? Sin perder de vista los apuntes hechos sobre los condicionantes de las fuentes documentales gaditanas (11), he estudiado cual podía ser el peso relativo del mercado negro del trigo y productos derivados en la ciudad. Analizando los expedientes abiertos en la provincia por el Tribunal de Contrabando referentes a incautaciones realizadas en la capital (sobre todo en el puerto y en los barrios del Pópulo, Santa María y Libertad) entre los años 1936 y 1941 (12) y que ascienden a un total de 304 , podemos observar que:

1.- La mayoría de expedientes abiertos responden a causas de contrabando de productos alimenticios, destacando ampliamente en este grupo el tabaco y el café $\left(68^{\prime} 6 \%\right.$ y $12,6 \%$, respectivamente) (cuadro 2). El contrabando de tabaco,canalizado a través del personal de la fábrica de la calle Plocia y por el muelle, llegó a ser tan importante que desde temprano estuvo encargado de su 
persecución el Servicio de Vigilancia de la Compañía Arrendataria de Tabacos (1936).

2.-Aunque las cantidades incautadas de los diversos productos varían mucho, no son corrientes los grandes alijos. En el caso del tabaco, por ejemplo, 66 de los 80 expedientes abiertos en 1941 lo fueron por incautaciones de cantidades inferiores a los $5 \mathrm{Kgs}$. (cuadro 3). No obstante, hay algunos alijos que llaman la atención por su volumen como, por ejemplo, los $242 \mathrm{kgs}$. de café y 102 de azúcar interceptados por la Guardia Civil en 1941 (13).

3.-Sólo hay un expediente en el que se documenta la incautación de harina de trigo, concretamente $15 \mathrm{Kgs}(14)$.

¿A qué se debe este mutismo de los expedientes respecto al mercado negro de trigo y derivados en Cádiz?. ¿No existía?, ¿serían demasiado hábiles los contrabandistas?. La causa se encuentre quizás en que la persecución de este tipo de delito tan específico no era función prioritaria del Tribunal de Contrabando, que atendía sobre todo los fraudes aduaneros, y era competencia más bien de la Fiscalía Provincial de Tasas o de la Inspección de la Delegación Provincial de la C.G.A.T. Continuando por este camino, podemos ver que posibilidades nos ofrece la documentación emanada de este Inspección Provincial sobre multados por acaparamiento y ocultación de productos panificables. Aunque los datos que ofrecen estos libros de registros de multas no permiten establecer una clara cuantificación (15), sí nos hacen posible afirmar que existió en Cádiz un mercado negro de trigo, harinas y pan. El libro de registro de los años 1939-1940 arroja un bajo porcentaje de sanciones por acaparamiento, ocultación o abuso en los precios (16). Sin embargo, no deja de ser orientativo, al igual que el libro del período 1948-1952 (17), donde encontramos, por ejemplo, un expediente abierto en 1949 por tenencia clandestina de 540 raciones de pan de $3^{\text {a }}$ categoría (10 grs. c/u) y 10 de $1^{\text {a }}(80$ grs. c/u $)(18)$, así como la falta de $611 \mathrm{Kgs}$. de harina en las existencias.

Evidencias del acaparamiento y la ocultación por parte de los productores de trigo podríamos encontrarlas, como lo hace Moreno en Alicante (1995: 180181), en las relaciones que el S.N.T. hace de los agricultores que no entregan el cupo forzoso de trigo y otros cereales. Sin embargo, las peculiaridades ya citadas de la documentación de la Delegación gaditana del S.N.T. limitan el acceso a la misma y no he localizado listas con estos contenidos (19). Contamos, sin embargo, con testimonios menos directos pero válidos que confirman la existencia de estas actividades, como los testimonios orales de pequeños propietarios (20), en el caso del acaparamiento y ocultación de la materia prima; o la preocupación que manifestaban las autoridades por perseguir a través de las diferentes inspecciones de la Guardia Civil y la Fiscalía de Tasas la práctica del comercio ilegal de harinas y pan. Esta labor de vigilancia, no obstante, no 
acabaría con el mercado negro, que no se extinguiría sino con la abolición del régimen de racionamiento y la declaración de la venta libre del pan (1952) (21).

\subsection{La persecución por las autoridades.}

Las autoridades del régimen franquista pusieron, en teoría, un gran empeño en combatir y erradicar el mercado negro. Estaban convencidos de que su existencia era la causa inmediata del desabastecimiento que sufría la población. Las medidas puestas en práctica por los organismos pertinentes, la C.G.A.T. principalmente, consistían en sanciones económicas (22), sin llegar a descartarse otro tipo de castigos de acuerdo a la responsabilidad penal del inculpado (23). En 1940, persistiendo los fraudes e infracciones en materia de precios y racionamiento, el Gobierno crea la Fiscalía Superior de Tasas (24) organismo que concentrará las funciones de erradicación de este tipo de delitos. Pero a pesar de estas medidas, el mercado negro no se resentía y continuaba creciendo. Ello se debía a los altos beneficios que aportaba a los implicados en él, lo que compensaba el riesgo de las sanciones, y al escaso celo o a la «venta» del silencio que caracterizaban a numerosos funcionarios de la Fiscalía de Tasas e Inspecciones de las distintas delegaciones de la C.G.A.T. (Eiroa 1995: 124).

El régimen incrementó las medidas represivas con la promulgación de la Ley de 16 octubre 1941 contra el Acaparamiento y la Ocultación (25), cuya principal característica fue la aplicación del Código Penal Militar a las causas de acaparamiento y ocultación.Así, los detenidos por delitos de este tipo serían juzgados «sumarísimamente» por un Consejo de Guerra. La aplicación de esta ley vino acompañada por una campaña de prensa a nivel nacional atacando a los estraperlistas, animando a la población a denunciarlos y defendiendo la rectitud y justicia de las duras medidas impuestas (26). La efectividad de estas medidas fue muy relativa y más bien escasa y puntual. Ciertamente, los volúmenes de mercancías comprados y vendidos en el mercado negro del trigo (que es el que nos ocupa) bajaron (Barciela y García 1983: 198, gráfico 2), pero no lo hicieron del modo espectacular que el gobierno esperaba. Nuevamente, la actitud de los funcionarios de la Inspección y la incapacidad del gobierno por satisfacer la demanda de alimentos, harán que el mercado negro siga siendo la única vía para garantizar la subsistencia de la población, aunque a costa del enriquecimiento de los grandes (y no tan grandes) estraperlistas.

\section{LA SITUACION DE LA PANADERIA GADITANA EN LOS AÑOS 40.}

\subsection{La organización del mundo laboral.}

El mundo de la panadería ha sido, por sus peculiares características (larga pervivencia de un proceso de elaboración artesanal con mínimas innovaciones técnicas a lo largo de siglos), uno de los que con mayor fuerza y durante más tiempo ha conservado sus rasgos gremialistas, asentados, al menos, desde finales del siglo XVIII (27). La clásica división del artesanado gremial tiene plena validez en el universo panadero hasta no hace muchos años. Incluso hoy 
día, las denominaciones y categorías se mantienen, aunque con bastantes matices. Esta estructura se compone, básicamente, de:

- Maestro panadero. Es el máximo responsable de la panadería. Suele coincidir con el industrial (o dueño de todos los medios de producción), aunque desde los años 40 se inicia un proceso de división de funciones por el que el industrial va abandonando poco a poco sus labores de maestría para ocuparse de la dirección y gestión de la panadería de la que es dueño.

- Oficiales. Son la mano de obra cualificada de la panadería. Controlados y coordinados por el maestro panadero, se ocupan de elaborar los productos. Los hay de diversas categorías -de primera y de segunda clase- y se ocupan de funciones específicas que les dan nombre: oficial de pala (encargado de hornear las piezas), oficial amasador (encargado de hacer la masa), etc.

- Aprendices. Son, habitualmente, muchachos jóvenes, menores de 14 años, que entran a trabajar en la panadería con el objeto de aprender el oficio y poder trabajar algún día como oficiales. No solían recibir sueldo, aunque sí se les pagaba con la parte de pan que correspondía a los trabajadores. Realizaban los trabajos más variopintos: limpieza, acarreo, etc.

El personal que trabajaba en las panaderías no solía ser muy numeroso y mantenían, a menudo, vínculos familiares. Por ejemplo, en la panadería sita en la calle Gloria 1 y 3 trabajaban entre 1939 y 1942 unas 6 personas, aproximadamente, de las que cuatro de ellas tenían algún tipo de relación familiar (28).

Por encima de la organización interna de la empresa, el régimen estableció desde 1945 el Grupo Nacional de Panadería de España, que sería incluido en la estructura vertical sindicalista del Estado dentro del Sindicato Nacional de Cereales, y que sustituía a la antigua Federación Nacional de Panaderos (VV.AA. 1993: 70) (29).

En 1946, el Ministerio de Trabajo emitió una orden por la que se aprobaba el Reglamento Naciónal del Trabajo en la Industria de Panadería (30). El inicio del proceso de mecanización de algunas panaderías desde los años 30 (31) obligó a distinguir en el nuevo reglamento entre panaderías totalmente mecanizadas y las parcial o nulamente mecanizadas. Los trabajadores de la industria panadera quedaban divididos en cuatro grandes categorías profesionales (32): los técnicos, presentes en las panaderías mecanizadas y encargados de su maquinaria; los administrativos, constituidos por el personal de gestión de la industria; los obreros, el grupo más numeroso y comprende a todos los obreros que trabajan directamente en la producción (maestros encargados, oficiales de pala, oficiales de masa, oficiales de mesa, ayudantes, aprendices, peones y pinches); los servicios complementarios (mayordomos, vendedores en despachos, repartidores a despachos y a domicilio y mujeres de la limpieza). 
La Reglamentación de 1946 regulaba también el acceso y sistemas de promoción interna de los trabajadores, muy similar, en esencia, al sistema gremial habitual desde el siglo XVIII: período mínimo de ejercicio y examen de aptitud (33). Se establece una edad mínima de acceso al trabajo en la panadería, dieciséis años (34), que sin embargo, según entrevistas que he mantenido con trabajadores del sector, no solía respetarse. También queda fijado el sistema de retribuciones, del que hablaremos más adelante (35).

El Reglamento también fija y normaliza todo el sistema de faltas y sanciones, definiendo los tipos de faltas (leves, graves y muy graves) y los supuestos que se incluyen en cada uno de ellos (36). Tampoco se omiten los horarios de trabajos, establecidos en ocho horas y con unos rendimientos mínimos obligatorios, las vacaciones, las horas extraordinarias y el descanso semanal (37).

Encontramos un lejano atisbo del espíritu gremial del sector, así como del populismo laboral del régimen, en el establecimiento de las bases para la creación, a instancias del Sindicato Vertical de Cereales, de un Montepío de Previsión de la Industria Panadera con el objeto de otorgar subsidios a parados forzosos y a jubilados (38). Un año más tarde, en 1947, serán aprobados los estatutos reglamentarios del Montepío Nacional de Previsión Social de Panaderos.

El reglamento de 1946, en suma, viene a reflejar el espíritu aplicado por el régimen en materia laboral, basado en el paternalismo del Estado, constituido como único interlocutor social válido a través de los distintos Sindicatos Verticales de ámbito nacional, y regulando las relaciones entre patronos y obreros. Es importante destacar, en este sentido, que en la Orden de 12 julio de 1946 no se recoge ningún mecanismo de mediación en conflictos laborales, pues estos no tienen cabida en el mundo laboral de los años 40 y dicha conflictividad es anulada por la vocación y por falsos mecanismos intermediarios, como las organizaciones sindicales (establecidas y controladas férreamente por el Estado) o la propia reglamentación que hemos tratado en las anteriores líneas.

\subsection{Condiciones de vida: la rentabilidad de las panaderías.}

El modo de vida del panadero de los años 40 , en el sentido más amplio del término, viene establecido no sólo por las condiciones de la regulación laboral que hemos tratado previamente, sino también por los beneficios y la rentabilidad que pueda aportar el trabajo en este sector. La panadería, como productora de un elemento básico e imprescindible de la dieta, estuvo sometida durante estos años a un férreo control por parte de las autoridades, que no descuidaron ni un solo paso del proceso productivo que culmina en el pan. Estas circunstancias, que ahora analizaremos más detalladamente, determinaron que la industria panadera tuviese serios problemas para obtener unas ganancias mínimas e incluso para poder sobrevivir. 
El objetivo básico de la intervención estatal en la panadería, harineras, molinerías y producción de trigo era el de garantizar a la población el acceso a precios bajos de un producto tan elemental como el pan. El control de la producción de trigo, a través del S.N.T. y de la C.G.A.T. era, como hemos visto, el primer paso. Para facilitar la labor reguladora y, al mismo tiempo, garantizar los intereses de los principales harineros, las Ministerios de Agricultura y el de Industria y Comercio, a través de los organismos competentes, mantuvieron una política de limitación del sector harinero. Se tendió a reducir el número de licencias para fábricas de harina y muchas se cerraron previa indemnización. (Villegas 1983: 191). Se permitió que algunos molinos se mantuvieran para uso particular, aunque en la práctica todos molían el cereal cuando les era entregado (Ib.: 191) (cuadro 5). Esta práctica fue también habitual en Cádiz, aunque solía llevarse a cabo con mucho más cuidado pues por el reducido número de fábricas de harina existentes -Castro, S.A. y Panificadora Eureka, S.A. (luego Harinera San Miguel, S.L., desde 1937)- el control era más eficaz.

La producción de las panaderías estaba condicionada por el cupo de harina que le adjudicase la C.G.A.T., así como por el rendimiento mínimo que se exigía a cada industria en función del número de trabajadores que tenía y de su grado de mecanización. Además, las panaderías sólo podían vender las cantidades que se les hubiese ordenado producir, debiéndolo hacer a los precios establecidos por la Junta Harino-Panadera o la Junta Provincial de Precios y de acuerdo a los mecanismos de control del consumo estipulados (sistema de las cartillas de racionamiento).

En estas condiciones, el beneficio del panadero en su tarea parecía poco menos que imposible. La legislación referente al establecimiento de los precios oficiales contemplaban un porcentaje de dicho precio en calidad del beneficio del industrial panadero, así como otro del industrial harinero (39). Pero este beneficio estaba lejos de compensar los gastos de producción, pues este porcentaje se establece sobre un precio oficial que no responde a los flujos reales de la oferta y la demanda. Estos precios inadecuados mostraron a lo largo de todo el período una tendencia inflacionista (gráfico 1). Si esto ocurría en el mercado oficial, indudablemente la situación sería mucho más drástica en el mercado negro del pan.

Para agravar la situación, la clientela de las panaderías no siempre podían pagar al contado y llegaban a acumular considerables deudas (Villegas 1983: 191-192). En el caso de Cádiz, por ejemplo, la panadería por excelencia del barrio de Santa María (la ubicada en la calle Gloria), se veía obligada a menudo a vender su producción fiando a sus clientes fijos, la mayoría, cuyo nivel adquisitivo medio era bastante bajo (sus empleos -cuando los tenían- solían ser como jornaleros, peones de obra, etc.).

Pero la paradoja más grande de todo este maremagnum de problemas y limitaciones es que la demanda de pan no era satisfecha por los panaderos. Las trabas impuestas a la producción por los organismos estatales determinaban un 
nivel de facturación por debajo de lo demandado por la población. La escasez de trigo -real o por ocultación de los agricultores- era la causa principal de esta situación, junto a la ineficacia de las diversas entidades públicas el escaso conocimiento que de la economía demostraron los cuadros de mando del Gobierno franquista.

Ante todo este panorama no asombra en absoluto que la mayoría de los panaderos tuviesen que recurrir a otras vías para intentar aumentar a unos niveles aceptables los beneficios de las panaderías, cuestión más relacionada con la misma supervivencia del negocio que con un oportunista afán de lucro. Los recursos más habituales eran la participación en el mercado negro y la práctica del fraude en la elaboración del pan, aunque respetando los canales oficiales de comercialización. En el segundo apartado de este trabajo ya nos ocupamos del mercado negro, por lo que ahora abordaremos las prácticas fraudulentas en la industria panadera gaditana (40).

El fraude solía centrarse en dos aspectos: reducir el peso de las piezas y utilizar ingredientes alternativos más baratos. El peso de las piezas de pan, al igual que sus precios, eran establecidos por las Juntas Harino-Panaderas (luego, por las Juntas Provinciales de Precios) y variaban en función de la categoría a la que pertenecían y/o según la coyuntura económica (cuadro 1). El sistema más empleado para reducir el peso de una pieza sin disminuir mucho su tamaño era el de añadir más cantidad de agua y masar más la mezcla. Esto empeoraba notablemente la calidad del pan, sobre todo en un clima especialmente húmedo y caluroso como el de Cádiz. La Fiscalía de Tasas y la Inspección de Abastos del Ayuntamiento, conscientes de estas prácticas, realizaban frecuentes visitas a las panaderías (al menos una vez al año las inspecciones generales y varias veces al mes, incluso, las inspecciones municipales de peso), levantando las «actas de repeso de pan». En estas inspecciones un guardia municipal o funcionario de la Inspección de Abastos llegaba sin previo aviso a la panadería y elegía al azar uno o varios sacos de pan que serían llevados al Mercado Central de la plaza Libertad para efectuar su repeso. Si la balanza daba el mismo peso que había dado el panadero, no había problema. De hecho, muchas de las actas de repeso de pan registradas en el libro del Negociado $1^{\circ}$ de Abastecimientos (41) terminan siendo archivadas. Las más de las veces, sin embargo, solían pagarse de algún modo la visita del inspector; o bien con alguna multa o con algún obsequio por su cordialidad.

Otras veces, los panaderos buscaban recortar gastos utilizando ingredientes alternativos, como harina de maíz o harina de trigo de baja calidad (afrecho). La Inspección Municipal perseguía estos fraudes a través de visitar periódicas a las diversas panaderías de la ciudad (42). En ellas, el Inspector Municipal de Abastos, acompañado de un guardia municipal, procedía a recoger muestras de pan que serían remitidas, junto al informe del inspector, al Laboratorio Municipal, que emitiría su propio informe a la Inspección conteniendo los resultados del análisis y la multa propuesta, si procede. La persistencia de este tipo de fraude hace que se incremente a dos veces por semana las inspecciones 
en 1938 (43). A pesar del empeño de las autoridades por erradicarlo, esta práctica fraudulenta fue la más utilizada (44), pues era más difícil de percibir a simple vista y siempre podía achacarse la mala calidad del producto a factores aleatorios que escapan al control del panadero (el clima, la humedad, la calidad de la harina).

Hubo en Cádiz también panaderos más audaces que, dentro de la legalidad, buscaron otro tipo de solución a sus problemas. Este fue el caso de lá Harinera San Miguel, S.L., sita en la calle Diego Arias (45). El proyecto -gestado por D. M. Ruiz García, industrial panadero domiciliado en la calle Gloria, y por D. J. Dueñas Salomón, director-gerente de la compañía mercantil citada- consistía en concentrar la producción de sus panaderías en una sola, de manera que los gastos de producción se redujesen, al repartirse entre dos, y se cubriese la demanda de pan que la Harinera San Miguel no siempre podía satisfacer. Al mismo tiempo, podía aprovecharse la infraestructura de venta de la compañía (46). Este proyecto, puesto en práctica desde 1948, dio un salto cualitativo en 1953 al constituirse en Sociedad Anónima (47). Este hecho se relaciona estrechamente con la abolición del sistema de racionamiento y la declaración de la venta libre del pan en 1952. A pesar de todo esto y de las buenas perspectivas, el conservadurismo tradicional de los panaderos, reacios a la innovación, y la falta del compromiso necesario por parte de unos pocos, llevaron el proyecto de una gran panificadora a terminar sus días agónicamente en 1963 (48).

Los problemas que he tratado hasta aquí afectaron también, y en mayor medida por su condición económica menos favorecida, al personal que trabajaba en las panaderías. En el caso de Cádiz, donde no hubo pan de panaderías industriales como en Barcelona, Sevilla o Madrid, el número de empleados no solía ser muy elevado. Las reducciones de plantillas y la no creación de empleo, consecuencias lógicas de las limitaciones impuestas al beneficio económico del industrial, provocaron que el paro en el sector fuese estimable. Este era más elevado en la categoría de oficiales, pues los industriales, para ahorrar, preferían contratar a aprendices o pinches para ejerciesen las funciones de oficialía pero cobrando sueldos de aprendices (49).

Los salarios de los obreros panaderos solía cobrarse por jornadas y según la cantidad de pan elaborada (50), y se recibía tanto en metálico como en especies, teniendo derecho el trabajador a una cantidad de pan, de acuerdo a lo estipulado en el contrato (51). Los sueldos percibidos por los obreros no eran elevados y tienden a disminuir en los primeros años de la posguerra (Eiroa 1995: 150, tabla 17). La situación cambia en 1946 con la aprobación del Reglamento Nacional del Trabajo en la Industria de Panadería (52), que establece los criterios para fijar los sueldos-base de los empleados: la zona en la que se localiza la industria panadera (53) y la categoría profesional y el cargo que ocupe cada trabajador (cuadro 4). El sueldo final puede verse incrementado por motivos varios como gratificaciones, plus por cargas familiares, etc. (54). La Regulación de 1946 mejoró sin duda las condiciones de trabajo de los empleados de la panadería. No obstante, mientras no hubiese un cambio en los sistemas de intervención del 
Estado que permitiesen un cierto crecimiento económico al sector de la panadería, casi estrangulado por el corsé del racionamiento, no podría esperarse una mejora sustancial en los modos de vida de aquellos que, de un modo u otro, sobrevivían con las manos en la masa.

\section{CONCLUSIONES.}

A lo largo del presente artículo he analizado someramente algunos de los aspectos que he considerado de mayor interés para un conocimiento inicial de la problemática que supone el estudio de la organización del abastecimiento y la producción de pan en unos años marcados por las terribles consecuencias de una guerra civil. A modo de recapitulación podemos concluir lo siguiente:

- La política de abastecimientos practicada por el régimen franquista entre 1939 y 1952 estuvo caracterizada por el intervencionismo del Estado que se concretó en la creación de una serie de organismos y mecanismos de control de la producción de alimentos, su distribución y su consumo. Esta política ignoró la realidad económica del país, en una mezcla de incapacidad técnica, deficiencias de las estadísticas, y arrogancia, despreciando las más elementales leyes económicas y confiando ciegamente en la fuerza sancionadora del Estado.

- A pesar de la insistencia del régimen por mantener esta política durante los años 40 , se mostró, en general, insuficiente para satisfacer las necesidades mínimas de la población española. La rigidez del sistema sólo dejaba una salida a la población para obtener los productos de los que era deficitaria: recurrir a las vías ilegales de comercialización, el mercado negro.

- En el caso concreto de Cádiz, la situación del abastecimiento, tanto el legal como el ilegal, era similar al del resto de España. No obstante, encontramos algunos matices importantes con otras regiones peninsulares. Comparando los resultados de las modestas investigaciones que he llevado a cabo con las realizadas con profundidad por Moreno Fonseret para la provincia de Alicante, podemos llegar a la conclusión de que el mercado negro de trigo, muy importante en el Levante, no parece tan fundamental en Cádiz capital, según nos muestran las fuentes consultadas. No dudo de su existencia, pues podemos encontrar evidencias indirectas de que lo hubo, pero es necesario recurrir a la consulta de otras fuentes diferentes que pudiesen iluminarnos sobre este aspecto. La clave esté, quizás, en ampliar el ámbito geográfico de este estudio a toda la provincia para obtener una visión de conjunto que oriente la investigación en esta ciudad.

- La panadería fue, después de la población, una de las grandes perjudicadas por el sistema de distribución y consumo oficiales. Las dificultades con las que tuvo que enfrentarse este sector (escaso/nulo margen de beneficios, limitaciones en la elaboración, distribución y venta del producto, etc.) provocaron por parte de los profesionales distintas respuestas a esa situación adversa. La más extendida fue, sin lugar a dudas, el recurso a las vías ilegales de 
comercialización, tanto para adquirir la materia prima (aunque ya hemos hablado de los problemas que hay para probar cuantitativamente el peso de los productos panificables en el mercado negro gaditano) como para poner en circulación el producto, buscando en lo posible un mayor margen en los beneficios a percibir.

- En último lugar, queda sólo por recordar que este trabajo pretende ser una introducción más que un estudio minucioso. El tiempo y las diversas dificultades comentadas en la introducción me han obligado a ello, así como el propio carácter de este texto como un trabajo de curso. En cualquier caso, creo que han quedado abiertas algunas incógnitas y, además, las posibles vías para orientar su resolución y el planteamiento de nuevas interrogantes. Huelga decir que, aún en un mundo tan aparentemente simple como el de la panadería (apariencia ficticia), son muchas las cosas que quedan por hacer, sobre todo, en el campo de acción de la Historia.

\section{BIBLIOGRAFIA.}

- ABELLA BERMEJO, R. (1985), La vida cotidiana en España bajo el régimen de Franco. Barcelona.

- BARCIELA LÓPEZ, C. (1983), «Producción y política cerealista durante la guerra civil española, 1936-1939». En G. Anes et al., Historia Económica y pensamiento social. Madrid. pp. 649-675.

- (1985), «Intervencionismo y crecimiento agrario en España (1936-1971)». En P. Martín Aceña y L. Prados de la Escosura, La nueva historia económica en España. Madrid, pp.

- (1986), «El mercado negro de productos agrarios en la posguerra, 1939-1953». En J. Fontana, España bajo el franquismo. Barcelona, pp. 192-205.

- (1987), «Crecimiento y cambio en la agricultura española desde la guerra civil». En J. Nadal et. al. (eds.), La economía española en el siglo XX. Barcelona. pp. 258-279.

- BARCIELA LOPEZ, C. y CARRERAS, A. (1989), Estadísticas históricas de España. Siglos XIX-XX. Madrid.

- BARCIELA LOPEZ, C. y GARCÍA GONZÁLEZ, A. (1983), «Un análisis crítico de las series estadísticas de los precios del trigo entre 1937 y 1950». Agricultura y Sociedad, 29: , Madrid. También publicado en R. Garrabou et. al. (eds.), $H^{a}$ Agraria de la España Contemporánea, 3: El fin de la agricultura tradicional (1900-1960). Barcelona, 1986. pp. 499-533.

- CLAVERA, J., (1976), «El estraperlo en los años 40». Información Comercial Española, 514: , Madrid. 
- EIROA SAN FRANCISCO, M., (1995), Viva Franco. Hambre, Racionamiento, Falangismo. Málaga, 1939-1942. Málaga.

- MILLÁN CHIVITE, J.L., (1993), Cádiz Siglo XX: del Cádiz hundido al Cádiz que resurge (1898-1979). Madrid.

- MINISTERIO DE AGRICULTURA, PESCA Y ALIMENTACIÓN, (1991), Estadísticas históricas de la producción agraria española, 1859-1935. Madrid.

- MORENO FONSERET, R., (1990), «El racionamiento alimenticio en la provincia de Alicante durante la posguerra». En Actas del Congreso de Jóvenes Historiadores y Geógrafos, II, Madrid, pp. 921-933.

- (1993), «Movimientos interiores y censos de racionamiento en la inmediata posguerra». Investigaciones Geográficas, 11: 309-316.

- (1994), La Autarquía en Alicante (1939-1952). Alicante.

- VILlEGAS, A. y ESCALERA, J., (1983), Molinos y panaderías tradicionales. Madrid.

- VV.AA., (1993), «Los precios del pan». Molinería y Panadería, 1000: 70-74, Barcelona.

\section{NOTAS.}

(1) Quiero expresar mi agradecimiento a todos aquellos que me han ayudado a culminar este trabajo, muchos sin duda, facilitándome el acceso a la documentación, aportando sus enriquecedoras apreciaciones personales y colaborando en todo lo necesario.

(2) Vid. también TORRES, M. (1944), El problema triguero y otras cuestiones fundamentales de la agricultura española. Madrid, donde el autor advierte sobre los efectos negativos de esta política de precios de tasa (Cit. en Barciela 1985: 301).

(3) El antecedente inmediato de la C.G.A.T. fue el Servicio Nacional de Abastecimientos y Transportes (creado por el Decreto de la Vicepresidencia de 16 febrero 1938, BOE 485, 18 febrero 1938). La célula básica de la C.G.A.T. fue creada en 1939 (Decreto de 28 abril, BOE, 121, 1 mayo 1939) y se constituyó definitivamente en 1941 (Ley de 24 junio 1941, BOE, 178, 27 junio 1941). La ley se aplicó en virtud del decreto de 11 de julio 1941, BOE, 202, 21 julio 1941). El organismo permanecerá en vigor con pequeñas modificaciones (Decreto de 7 mayo 1942, BOE, 140, 20 mayo 1942) hasta una nueva remodelación en 1968 
y desaparecerá en 1981 (Real Decreto de 4 diciembre, BOE, 298, 14 diciembre 1981).

(4) Las Juntas Harino-Panaderas fueron creadas por el art. 82 del Reglamento de 6 octubre 1937 (BOE, 352, 6 octubre 1937) para aplicación del Decreto-Ley de Ordenación Triguera de 23 agosto 1937 (BOE, 309, 25 agosto 1937). En 1945, la Circular $n^{\circ} 511$ de 12 marzo 1945 emitidas por la C.G.A.T. (Revista de Legislación de la C.G.A.T., II, 1945), pp. 254-291) crea las Juntas Provinciales de Precios, que absorberían a las Juntas Harino-Panaderas y asumirán sus funciones.

(5) El sistema de racionamiento fue establecido por la Orden de 14 mayo 1939 del Ministerio de Industria y Comercio (BOE, 137, 17 mayo 1939). El reparto de los recursos se organizaba basándose en los censos de racionamiento municipales (luego, Ficheros Individuales de Racionamiento), donde se registraba la población existente por unidad familiar. La cuantía de las raciones y su recepción puntual se controlaba por medio de cartillas familiares, primero, e individuales, después (Decreto de 6 abril 1943, BOE, 105, 15 abril 1943). Bibliografía sobre el régimen de racionamiento la encontramos en Abella 1985, Eiroa 1995, Moreno 1990, Moreno 1993, Moreno 1994.

(6) Para la evolución de los precios oficiales y los estimados del mercado negro, vid. Barciela y García 1983: 508, cuadro 1. Para profundizar en los mecanismos económicos que rigen el mercado negro puede consultarse: BARCIELA 1985: 285-294; TORRES, M. de (1940), «De los efectos de la intervención en los precios de la producción agraria», Agricultura; PLUMTRE, A. (1947), «The theory of the Black Market: Forther Considerations», Canadian Journal of Economics and political Science (cit. en Barciela 1985: 288, nota 3).

(7) Para una răpida impresión sobre la evolución de los jornales en el territorio nacional, vid. Eiroa 1995: 150, tabla 17.

(8) A este respecto no he hallado fuentes que me informasen, pues ni la documentación depositada en el AHPCA ni la exigua contabilidad de algunas industrias panaderas de Cádiz que han sobrevivido hasta hoy, arrojan ninguna luz sobre el asunto.

(9) Un mapa general de las áreas deficitarias lo encontramos en Barciela 1983: 671. Es interesante observar los contrastes entre provincias deficitarias como Cádiz y Alicante (Moreno 1995) y otras excedentarias (MINISTERIO DE AGRICULTURA, PESCA Y ALIMENTACION (1991), Estadísticas históricas de la producción agraria española, 1859-1935, Madrid, pp. 144, $336,1101)$.

(10) Al respecto, y como ejemplo, puede verse AHPCA (Archivo Histórico Provincial de Cádiz), Sección Hacienda, Tribunal de Contrabando (1936), c. 1509, exp. 55. 
(11) Vid. sup. 6.

(12) AHPCA, Sección Hacienda, Tribunal de Contrabando, expedientes 1936 (c. 1509), 1937-1939 (c. 1510), 1939 (c. 1511), 1940 (cc. 1512 y 1513), 1941 (cc. 1495, 1515, 1516, 1517). Los fondos del archivo llegan hasta los años 70 , pero he seleccionado estos años por ser inmediatamente posteriores a la guerra y al establecimiento del sistema de precios de tasa por el S.N.T. (1937). Por otro lado, 1941 es el «año culmen del racionamiento» (Eiroa 1995: 114).

(13) AHPCA, Sección Hacienda, Tribunal de Contrabando (1941), c. 1516, exp. 409.

(14) AHPCA, Sección Hacienda, Tribunal de Contrabando (1941), c. 1515, exp. 240.

(15) Quizás sería posible si se estudian uno a uno cada expediente abierto, conservados todos ellos en el AHPCA, aunque sin catalogar.

(16) AHPCA, Sección Abastecimientos, Libro registro de multas del negociado $1^{\circ}$ de Abstecimiento (1939-1940), 1. 1289.

(17) AHPCA, Sección Abastecimientos, Libro registro de multas (1948-1952), 1. 1286.

(18) Peso por ración según BOPCA (Boletín Oficial de la Provincia de Cádiz); 10, 14 enero 1949.

(19) Sí me facilitaron en el AHPCA, no obstante, unas relaciones del S.N.T. de Jerez remitidas por la Inspección General de la C.G.A.T. sobre «los agricultores que se han comprometido a entregar cupos de avena y cebada» (1947) sin clasificar ni catalogar (en depósito provisional en el AHPCA) que podrían servir, si apareciese documentación similar, para aportar más información sobre la ocultación de cereales en Cádiz.

(20) Mi agradecimiento a D. Cristóbal Sánchez García por la información que me ha dado sobre las actividades ilegales practicadas en el término de Chiclana y de las que él era testigo no implicado.

(21) El régimen de racionamiento finalizó con la orden publicada en el BOE, 87, 27 marzo 1952 (también en BOPCA, 80, 5 abril 1952). La ineficacia de las autoridades para acabar con este mercado ilegal se reflejan en las órdenes reiterativas que pronuncia el Gobernador Civil hasta fechas avanzadas (por ejemplo, 1951: BOPCA, 207, 11 septiembre 1951).

(22) Consultar Decreto de 23 de agosto 1937, arts. transitorios 5-7 (BOE, 309, 25 agosto de 1937); Decreto 28 abril de 1939, art. 11 (BOE, 121, 1 mayo 1939). 
(23) Decreto-Ley 23 agosto 1937 de Ordenación Triguera, art. 12 (BOE, 309, 25 agosto 1937).

(24) Ley de 30 agosto 1940 (BOE, 277, 3 octubre 1940) y Reglamento de Fiscalía Superior de Tasas (BOE, 286, 13 octubre 1940).

(25) BOE, 22 octubre de 1941.

(26) Por ejemplo, «Diario de Cádiz», 23 de octubre de 1941, 13 de diciembre de 1941.

(27) Ordenanzas del Gremio de Panaderos de 1720. AHMC (Archivo Histórico Municipal de Cádiz), Sección Cabildos (1720), ff. 327v-339v.

(28) Debo esta información al amable testimonio de $D^{a}$ María Marchante, viuda de D. J. García, gerente de la panadería entre 1923 y 1962.

(29) Sobre el Grupo Nacional de Panadería no he encontrado información donde la he buscado: en la documentación de la A.I.S.S. depositada en el AHPCA.

(30) Orden de 12 julio 1946 (BOE, 200, 19 julio 1946).

(31) En Cádiz, por ejemplo, la panadería de la calle Gloria instaló en 1926 la primera máquina de la empresa: una amasadora mecánica movida por un motor eléctrico (Documentación privada de la empresa).

(32) Orden de 12 julio 1946. Cap. III, secciones $1^{\mathrm{a}}$ y $2^{\mathrm{a}}$.

(33) Ib. Cap. III, sección $4^{2}$.

(34) Ib., Cap. III, sección $5^{\text {a }}$.

(35) Vid. inf., apartado 3.2.

(36) Orden de 12 julio 1946. Cap. VI, secciones $1^{\mathrm{a}}, 2^{\mathrm{a}}$ y $3^{\mathrm{a}}$.

(37) Ib., Cap. V.

(38) Ib., Cap. VII.

(39) En el caso del panadero, el beneficio máximo es de 0,03 pts. por $\mathrm{kg}$. de pan (1937) -decreto 23 agosto 1937 art. 11, BOE, 309, 25 agosto 1937)- y de 0,08 y 0.20 pts. por hg. de pan de tercera y primera según cada categoría, respectivamente (1945) -Circular $\mathrm{n}^{\circ} 511$ de 12 de marzo de 1945, 47, C.G.A.T., Legislación de C.G.A.T., II, 1945, p. 254-291). 
(40) Las fuentes de que disponemos para tratar sobre este asunto se reducen a las siguientes: libros de registro de expedientes y multas del Negociado $1^{\circ}$ de Abastecimientos (1939-1952), conservados en el AHPC, informes expedidos por el Laboratorio Municipal de Higiene a petición de la Inspección de Abastos (1938), conservados en el AHMC (Sección Abastos, Inspección de Abastos, Análisis de pan (1938), c. 7508, exp. 36); órdenes y circulares publicadas en el BOPCA (especialmente la del $n^{\circ} 207$ de 11 septiembre 1951); testimonios orales de panaderos; circulares de la C.G.A.T.

(41) Vid. sup. nota anterior.

(42) Esta labor celosa de la Inspección Municipal de Abastos pasará a ser coordinada y dirigida desde 1940 por la Fiscalía Superior de Tasas a través de sus Delegaciones Provinciales (vid. sup., nota 20).

(43) AHMC, Sección Abastos, Inspección de Abastos, Análisis de pan (1938), c. 7058 , exp. 36 .

(44) Por ejemplo, en los libros de registro de multas de 1939-1940, 29 de los 38 panaderos multados lo han sido por vender pan de mala calidad (AHPC, Sección Abastecimiento. Libro registro de multas 1939-1940, L. 1289).

(45) La compañía fue constituida en 1937 y heredaba las instalaciones e infraestructura de la Panificadora Eureka S.A., antigua titular de las mismas.

(46) No se conserva una documentación amplia sobre los primeros años de esta asociación industrial. Gran parte de la información se ha obtenido por el testimonio oral de los sucesores de Ruiz García y Dueñas Salomón, a quienes les agradezco su colaboración. He accedido sólo a un documento escrito, una copia de escritura del contrato de arrendamiento otorgado por D.M. Ruiz a favor de la Harinera San Miguel S.L. (7 septiembre 1948)(Documentación privada de «Sucesores de Manuel Ruiz García S.L.», Cádiz). Sin duda, los fondos del Registro Mercantil deben contener toda la documentación financiera emanada de dicha entidad, si bien no me ha sido posible acceder aún a ella.

(47) Existe una copia del documento de constitución de Harinera San Miguel S.A. (1952)(Documentación privada de «Sucesores de Manuel Ruiz García. S.L.», Cádiz).

(48) La penosa situación de la Sociedad en estos últimos años la conocemos gracias al testimonio de D.J. Dueñas, hijo de uno de los fundadores, y al Libro de Actas de la Junta de Accionistas de la Harinera San Miguel, S.A. (19621963), conservado por la misma persona.

(49) No cuento con datos numéricos para apoyar esta afirmación, pero algunas noticias sueltas evidencian la veracidad de la situación. Tal es el caso del aviso 
que hace el Gobernador Civil de Cádiz a los panaderos sobre la contratación de aprendices y pinches como oficiales (BOPCA, 54, 6 marzo 1951).

(50) En una carta del alcalde de Sanlúcar de Barrameda al de Cádiz (septiembre de 1936) preguntándole sobre el precio del pan familiar dice que «los obreros cobran de los patronos por unidad kilo de pan familiar que elaboran» (AHMCA, Sección Pósito. Negociado de Abastos, C. 7059, exp. 80).

(51) Los contratos de trabajo rara vez se realizaban por escrito, siendo lo más habitual que fuesen apalabrados, lo que debía suponer un riesgo para la estabilidad laboral del obrero.

(52) Vid. sup., nota 30.

(53) El artículo 23 de este Reglamento dividía el territorio nacional en cinco zonas diferentes, según criterios, al parecer (no los especifican), de número de habitantes y niveles de renta. La provincia de Cádiz queda incluida en la segunda zona. Los salarios disminuyen progresivamente de la $1^{\mathrm{a}}$ a la $5^{\mathrm{a}}$ zona, con diferencias de hasta un $40 \%$.

(54) Orden de 12 julio 1946 (Vid. sup., nota 30), arts. 27 a 31. 


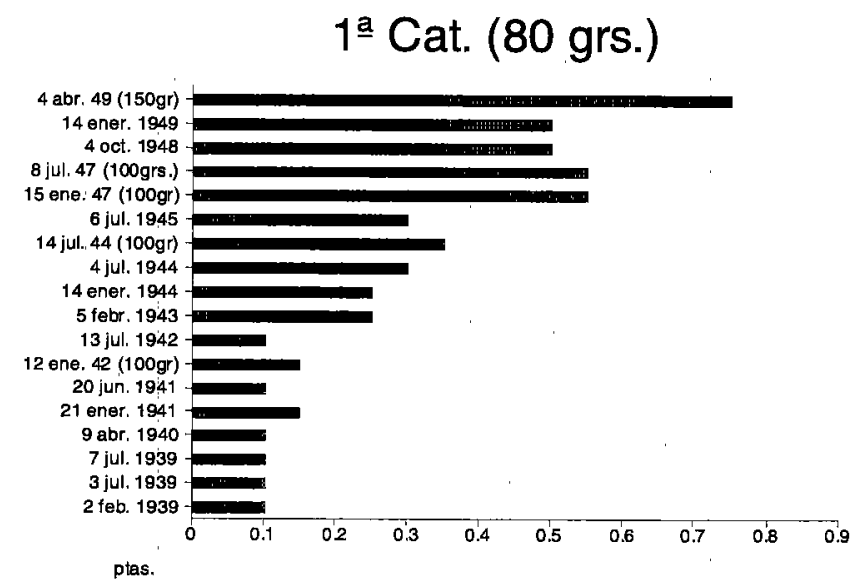

GRÁFICO 1. Precios del pan en Cádiz (1939-1952) (1ªtegoría).

CUADRO 1: Precios y raciones-tipo del pan (1939-1952). (1 categoría).

\begin{tabular}{||l|l|l||}
\hline \multicolumn{1}{|c|}{ DíA-MES } & \multicolumn{1}{|c|}{ AÑO } & \multicolumn{1}{|c|}{ Grs./precio } \\
\hline 2-febrero & 1939 & $80^{\prime} / 0^{\prime} 10$ \\
\hline 3-julio & 1939 & $80 / 0^{\prime} 10$ \\
\hline 7-julio & 1939 & $80 / 0^{\prime} 10$ \\
\hline 9-abril & 1940 & $80 / 0^{\prime} 10$ \\
\hline 21-enero & 1941 & $80 / 0^{\prime} 15$ \\
\hline 20-junio & 1941 & $80 / 0^{\prime} 10$ \\
\hline 12-enero & 1942 & $100 / 0^{\prime} 15$ \\
\hline 13-julio & 1942 & $80 / 0^{\prime} 10$ \\
\hline 5-febrero & 1943 & $80 / 0^{\prime} 25$ \\
\hline 14-enero & 1944 & $80 / 0^{\prime} 25$ \\
\hline 4-julio & 1944 & $80 / 0^{\prime} 30$ \\
\hline 14-julio & 1944 & $100 / 0^{\prime} 35$ \\
\hline 6-julio & 1945 & $7 / 0^{\prime} 30$ \\
\hline 15-enero & 1947 & $150 / 0^{\prime} 55$ \\
\hline 8-julio & 1947 & $1000^{\prime} 55$ \\
\hline 4-octubre & 1948 & $80 / 0^{\prime} 50$ \\
\hline 14-enero & 1949 & $80 / 0^{\prime} 50$ \\
\hline 4-abril & 1952 & $150 / 0^{\prime} 75$ \\
\hline \hline
\end{tabular}

FUENTE: Elaboración propia a partir del BOPCA (1939-1952). 

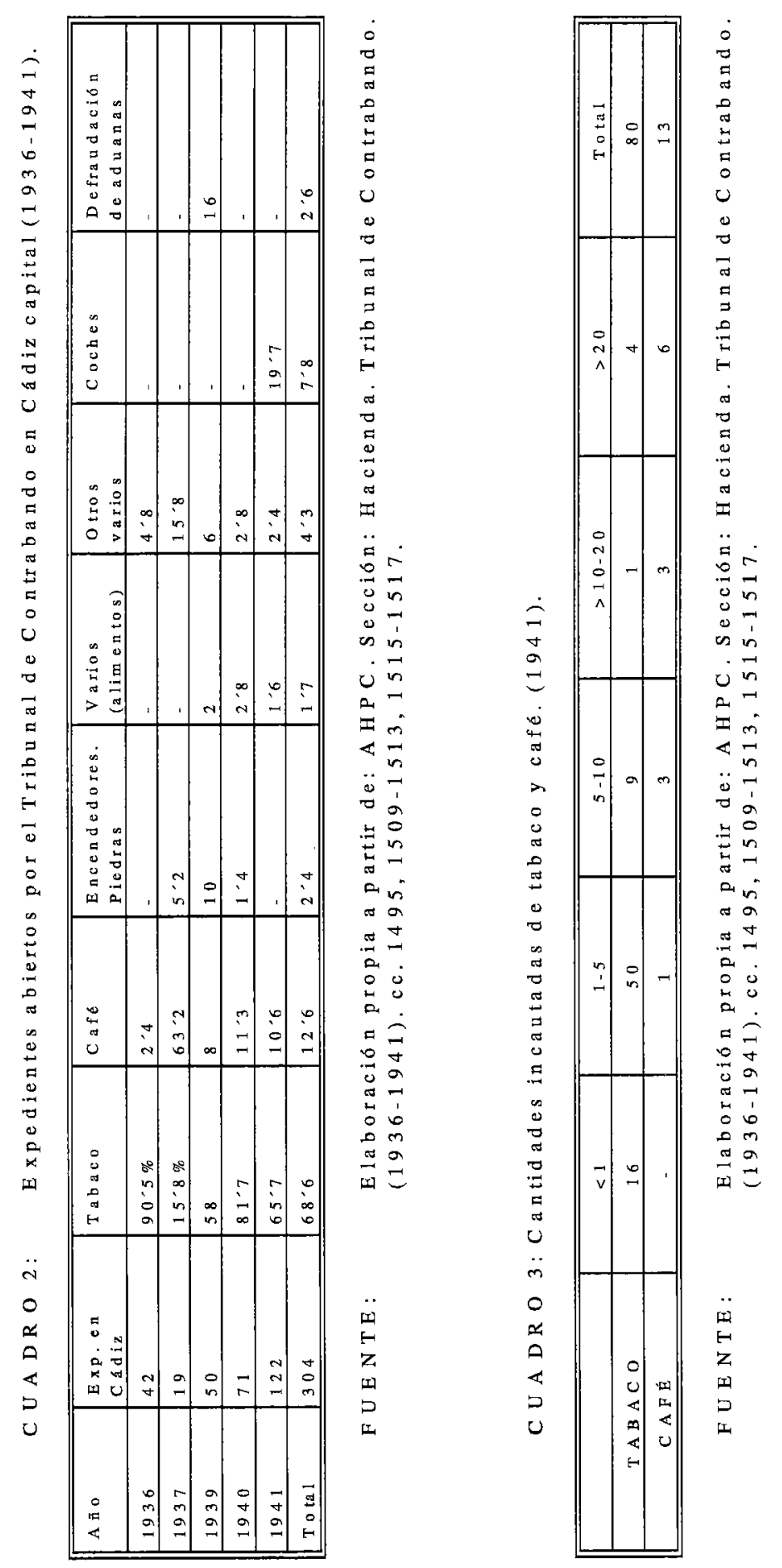
CUADRO 4. Retribuciones base del personal de panadería (2" zona). (1946).

\begin{tabular}{|c|c|}
\hline CATEGORIA PROFESIONAL & SUEL DO* \\
\hline $\begin{array}{l}\text { TÉCNICOS: } \\
\text { - Jefe de Fabric ación } \\
\text { - Jefe de Talter Mecánico }\end{array}$ & $\begin{array}{l}900 \\
850 \\
\end{array}$ \\
\hline $\begin{array}{l}\text { ADMINIS TR ATIVOS: } \\
\text { Jefe de Oficina y Contabilidad } \\
\text { - Oficial Admizistrativo } \\
\text { - Auxiliar de Oficina } \\
\end{array}$ & $\begin{array}{l}900 \\
750 \\
450 \\
\end{array}$ \\
\hline $\begin{array}{l}\text { OBRER OS: } \\
\text { - Maestro encargado } \\
\text { - Oficial de pala } \\
\text { - Oficial de mana } \\
\text { - Oficial de mesa } \\
\text { - Ayudante } \\
\text { - Aprendiz } 1^{\text {er año }} \\
\text { - Aprendiz } 2^{\mathrm{n}} \text { año } \\
\text { - Peón } \\
\text { - Pinche de } 14 \text { a } 15 \text { años } \\
\text { - Vendedor en despacho } \\
\text { - Vendedora en despacho } \\
\text { - Mujer de la limpieza }\end{array}$ & $\begin{array}{l}2^{\prime} 50 \\
20 \\
19 \\
17 \\
15 \\
5 \\
8 \\
12 \\
6^{\prime} 50 \\
16 \\
12^{\prime} 80 \\
1^{\prime} 50 \\
\end{array}$ \\
\hline
\end{tabular}

Técnicos y Administrativon, sueldos mensuales; obreros, sueldos dinrios (excepto mujer de la limpieza por horas).

FUENTE: B OE, 200, 19 julio 1946. 
CUADRO 5. Molinos y almazaras de la provincia de Cádiz (1941?).

\begin{tabular}{|c|c|c|c|c|c|c|}
\hline TÉRMINO & Fäbress Hering & $\begin{array}{l}\text { Molinos } \\
\text { Maquileros }\end{array}$ & $\begin{array}{l}\text { Molinos de pienso } \\
\text { pera scryicio público }\end{array}$ & $\begin{array}{l}\text { Molino plenso y } \\
\text { trigo para servicio } \\
\text { püblico }\end{array}$ & $\begin{array}{l}\text { Molizo pienso uso } \\
\text { prricular }\end{array}$ & Almazms \\
\hline Alcalí de los Ganules & 1 & 3 & & 1 & 1 & 7 \\
\hline Alcaládel dalle & 1 & 4 & & & & 1 \\
\hline Algw & & 2 & & & & 1 \\
\hline Algeciras & 1 & 1 & & 1 & 1 & \\
\hline Algodonales & 1 & 5 & & 1 & & 7 \\
\hline Arcos & 2 & 1 & & 1 & 2 & 49 \\
\hline \multicolumn{7}{|l|}{ Bunteatc } \\
\hline \multicolumn{7}{|l|}{$\operatorname{Bamos}(\operatorname{Los})$} \\
\hline \multicolumn{7}{|l|}{ Benmocas } \\
\hline Bornos & 1 & 2 & & & 1 & 5 \\
\hline Bosque (E:) & 1 & 3 & & & & 3 \\
\hline Cídiz & 2 & & & & & \\
\hline \multicolumn{7}{|l|}{ Custellar } \\
\hline Conil & & 2 & 1 & & & \\
\hline Chiclana & 3 & & & 1 & 1 & 1 \\
\hline \multicolumn{7}{|l|}{ Chipiona } \\
\hline Eaper & 1 & & 2 & & & 8 \\
\hline Gastor (EI) & 1 & 1 & & & & $A$ \\
\hline Grazulem & 1 & 7 & & & 1 & \\
\hline Jerez de in Fr: & 6 & 1 & 2 & & 3 & 16 \\
\hline Jimen & 1 & 3 & 1 & 2 & 1 & \\
\hline \multicolumn{7}{|l|}{ Lo Lines } \\
\hline Medine Sidonan & 2 & 5 & 1 & 1 & & \\
\hline Olvest & 1 & 7 & 1 & & & 6 \\
\hline Paterna de Rivera & 1 & & 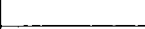 & & & \\
\hline Predo del Rey & 1 & & 1 & & & 4 \\
\hline Puerto de Sth M: & 1 & & 1 & & 2 & \\
\hline \begin{tabular}{|l} 
Puerto Ral \\
\end{tabular} & 1 & 1 & 1 & & & 2 \\
\hline Puento Sernano & & 1 & & & & 8 \\
\hline \multicolumn{7}{|l|}{ Rota } \\
\hline \multicolumn{7}{|l|}{ Sen Fernindo } \\
\hline Snn Roque & 1 & & & & & \\
\hline \multicolumn{7}{|l|}{ Snnticar } \\
\hline Sereni1 & 2 & 4 & 1 & & & 4 \\
\hline Terife & & 6 & & & & \\
\hline \multicolumn{7}{|l|}{ Torse Albiquime } \\
\hline \multicolumn{7}{|l|}{ Trebuenn. } \\
\hline Ubrnque & & 8 & & & & 2 \\
\hline V ejer de le Fia. & & 3 & 1 & & & \\
\hline \multicolumn{7}{|l|}{ Villaluenga Ros, } \\
\hline Villamartir & 1 & 2 & 1 & & & 18 \\
\hline Zahon de la Sierns & & & & & & 3 \\
\hline Zuhara de los Atunes & & & & & & \\
\hline
\end{tabular}

FUENTE: Elaboración propia a partir de AHPC. Sección: Mapas. Planero A3. 